\title{
Pflegeforschung an Uni Wien
}

\section{Kooperation mit Fachhochschule}

Vor etwa zehn Jahren begann auch in Österreich die Diskussion, Pflegewissenschaft auf universitärer Ebene zu etablieren. Nach der Möglichkeit ein individuelles Diplomstudium Pflege zu absolvieren, einer zeitlich befristeten Stiftungsprofessur in Wien, der Einrichtung einer Pflegewissenschaftlichen Abteilung an der Medizin Universität Graz und privaten Initiativen in Tirol und Salzburg sowie der Ansiedlung auf Fachhochschulniveau, ist der Lehrstuhl für Pflegewissenschaft nun endgültig an der Universität Wien eingerichtet.

Die Bachelorausbildung wird an die FH Campus Wien ausgelagert, Master- und Doktoratsstudium der Pflegewissenschaft werden an der Universität Wien angeboten. Die Berufungsfeier für Univ.-Prof. Dr. Hanna Mayer als Vorstand des Instituts für Pflegewissenschaft fand Ende März statt.
„Pflege ist ein interdisziplinäres Fach“, stellte der Rektor der Universität Wien, Univ.-Prof. Dr. Georg Winckler, fest: „Daher ist die Universität Wien der richtige Ort dafür." Gute Kontakte zur Medizin Universität Wien und eine Zusammenarbeit mit dem privaten Pflegeheimbetreiber SeneCura stellten den Bezug zwischen Wissenschaft und Praxis sicher. Wincklers Bitte: „Die Pflegewissenschaft an der Universität zu vertiefen, damit sie an der Uni Wien blühen und gedeihen kann."

Auf die Umsetzung der Bologna-Kriterien ging der Dekan der sozialwissenschaftlichen Fakultät, Univ.-Prof Dr Rudolf Richter ein und verwies darauf, dass das Kerngeschäft der Universität Master und PhD-Studien seien. Mit der Auslagerung des praxisbezogenen Bachelorstudiums an die FH Campus Wien sei es gelungen die wissenschaftliche Aktivität der Pflegewissenschaft an der Universität besonders hervorzuheben. Die neue Studienarchitektur könne und solle durchaus Vorbild für andere Bachelorlehrgänge sein, stellte Mayer fest. Die Forschungsschwerpunkte am Institut für Pflegewissenschaft der Universität Wien sind „Leben mit Krankheit/verändertem Gesundheitszustand“ und „pflegerische Interventionen" thematisch konzentriert man sich auf Familienpflege, onkologische Pflege und gerontologische Pflege. Für den internationalen Erfahrungs- und Erkenntnisaustausch existieren Kooperationen mit anderen Universitäten.

„Österreich ist ein Land, das nicht sehr begeistert über seine Universitäten ist", stellte Richter fest, „daher müssen wir den Studenten auch vermitteln, dass es sich auszahlt hier eine wissenschaftliche Ausbildung zu absolvieren." Und ganz speziell: „Es zahlt sich aus Pflegewissenschaft bei Prof. Mayer zu studieren!“ 